\title{
Resting Membrane Potential and Ionic Distribution in Fast- and Slow-Twitch Mammalian Muscle
}

\author{
David S. Campion \\ From the Department of Medicine, University of California at Los Angeles \\ School of Medicine, Los Angeles, California 90024
}

\begin{abstract}
A в S T R A C T The resting membrane potential and intracellular potassium and sodium concentration of three guinea pig hind limb muscles were studied. These properties are related to the gross color, the speed of contraction, and the biochemically defined fiber type composing the muscle. The resting membrane potential and intracellular content were: white vastus (grossly white, fasttwitch glycolytic) $-85.3 \mathrm{mV}$, potassium $171.9 \mathrm{meq} /$ liter; soleus (grossly red, slow-twitch oxidative) -69.7 $\mathrm{mV}$, potassium $137.5 \mathrm{meq} / \mathrm{liter}$; and red vastus lateralis (grossly red, fast-twitch oxidative glycolytic) - 71.7 $\mathrm{mV}$, potassium $139.6 \mathrm{meq} /$ liter. In soleus and red vastus lateralis, the relative permeability of sodium to potassium was 0.041 and 0.036 , while in white vastus it was 0.015 . These results give us the first exception to the hypothesis that fast-twitch fibers have higher intracellular potassium and higher resting membrane potential than slow-twitch fibers.
\end{abstract}

\section{INTRODUCTION}

The measured resting membrane potential (RMP) ${ }^{1}$ of human skeletal muscle is reported as ranging from -65 to $-90 \mathrm{mV}(1-7)$. This wide spread of values has largely been attributed to various technical difficulties or to inclusion of low RMP values found in superficial muscle fibers with the more consistent and higher values of deeper muscle fibers (8). Insufficient weight, however, has been given to the fact that both human and animal studies have demonstrated that mammalian muscle clearly consists of at least three different fiber types (9) that have differing biochemical and physiological functions (10). Any meaningful study

Received for publication 10 August 1973 and in revised form 31 January 1974.

1 Abbreviations used in this paper: ECF, extracellular fluid; $\mathrm{E}_{\mathrm{K}}$, potassium potential; ICF, intracellular fluid; $\mathrm{P}_{\mathrm{Na}}$ relative permeability figure for sodium/potassium; RMP, resting membrane potential. of muscle, such as measurement of RMP or electrolyte content, must include a determination of the precise type of fiber on which measurement is made.

As the basic function of muscle is contraction, it would seem most reasonable to classify muscle by its speed of contraction into fast-twitch and slow-twitch muscle; however, a simpler classification into white and red muscle has been made based on the generalization that fast-twitch muscles are white and slow-twitch muscles, red.

These aspects have been reviewed by Guth (11); Mark (12) ; Barnard, Edgerton, Furukawa, and Peter (9); and Peter, Barnard, Edgerton, Gillespie, and Stempel (10). The latter group in particular has shown that this generalization is not valid; some red skeletal muscles composed predominantly of fibers which are grossly red contract as rapidly as muscles composed of white fibers. In detailed studies of the metabolic profiles of guinea pig hind limb muscle, three distinct fiber types were described: fast-twitch glycolytic (white vastus lateralis), fast-twitch oxidative glycolytic (red vastus lateralis) and slow-twitch oxidative (soleus). Although it is now obvious that whole muscles cannot be simply categorized as "red" or "white", in earlier reports the ionic composition and RMP of muscles have, in fact, been related to gross color. Drahota (13), who in 1961 was the first to report the differences in the ionic composition of red and white fibers, suggested that muscles could be subdivided into two groups according to the ionic composition; those muscles that appeared grossly red having lower intracellular potassium and higher intracellular sodium than those muscles that appeared grossly white. Sreter and Woo (14) extended this observation in an extensive analysis of many muscles and also concluded that grossly red muscles, and the red part of muscles like gastrocnemius that had both red and white portions, had lower intracellular potassium than white muscles. 
The Hodgkin and Katz (15) and Goldman (16) theory of ionic diffusion predicts that the RMP will approximate the potassium potential $\left(E_{K}\right),{ }^{2}$ so that slowtwitch grossly red fibers should have a lower RMP than fast-twitch white fibers. Yonemura (17) and Federov (18) confirmed this, observing that the RMP of slowcontracting muscle fibers of the rat is lower than the RMP of fast-contracting fibers. The neural influence on the ionic composition of fast- and slow-contracting fibers was demonstrated by Hoh and Salafsky (19). In their experiments, cross union of the nerves to the fast-contracting extensor digitorum longus and slow-contracting soleus muscle resulted in a reversal of the normal potassium composition; intracellular potassium increased in soleus and decreased in extensor digitorum longus. For normal and self-innervated extensor digitorum longus, potassium inside the cell was 173.1 and $172.8 \mathrm{meq} / \mathrm{liter}$, respectively, whereas in cross-innervated extensor digitorum longus, intracellular potassium was $158.5 \mathrm{meq} /$ liter, a figure very close to the intracellular potassium of $154.3 \mathrm{meq} /$ liter found in a self-innervated soleus. It would seem, therefore, that almost all previous studies have confirmed the hypothesis that slow-contracting grossly red fibers have a lower intracellular potassium and lower RMP than fast-contracting grossly white fibers. We have tested this generalization by studying the RMP and the distribution of potassium, sodium, and chloride in guinea pig white vastus lateralis, red vastus lateralis, and soleus, three muscles that have very clearly defined and different physiological and biochemical properties.

\section{METHODS}

Measurement of RMP. 200-250 g guinea pigs anesthetized with intraperitoneal Nembutal ( $50 \mathrm{mg} / \mathrm{kg}$ ) (Abbot Laboratories, North Chicago, I11.) were used. The vastus muscle has an anterior white portion and lateral red portion. The grossly white portion is composed predominantly $(71 \%)$ of fast-contracting glycolytic fibers (time-to-peak tension $20 \mathrm{~ms}$ ), while the grossly red portion is composed predominantly $(78 \%)$ of fast-contracting oxidative glycolytic fibers (time-to-peak tension $19 \mathrm{~ms}$ ) (12). The fibers of the guinea pig soleus muscle, also grossly red in appearance, are entirely slow-contracting oxidative (time-to-peak tension $82 \mathrm{~ms}$ ) (12). Muscles of the thigh were exposed by an anterior incision, and in order to maintain the muscle warmed and so reduce twitching, castor oil at $38^{\circ} \mathrm{C}$ was continuously dripped over the muscle. RMP was measured with microelectrodes filled with $3 \mathrm{M} \mathrm{KCl}$, mounted in a silver/silver chloride electrode holder and having a resistance of 5-10 M $\Omega$. Only electrodes with tip potentials of less than $5.0 \mathrm{mV}$ were used. Reference electrode was a capillary filled with $3 \mathrm{M} \mathrm{KCl}$ and mounted on a matching silver/silver chloride electrode inserted subcutaneously in the abdomen. The high impedance side was connected to the input of a W-P Instruments model $\mathrm{M}-4 \mathrm{~A}$ Precision

$$
{ }^{2} \mathrm{E}_{\mathrm{K}}=61.5 \log \frac{\left(\mathrm{K}^{+}\right) \text {intracellular fluid (ICF) }}{\left(\mathrm{K}^{+}\right) \text {extracellular fluid }(\mathrm{ECF})} \text { at } 38^{\circ} \mathrm{C} \text {. }
$$

Electrometer (W-P Instruments, Inc., Hamden, Conn.) that allowed neutralization of junction potentials. Superficial fibers occasionally had a lower R.MP than deeper fibers, but in order to avoid bias, all potentials showing an abrupt shift from 0 to $40 \mathrm{mV}$ or more were included in the analysis. Soleus muscle was exposed by a posterior incision with separation of the gastrocnemius muscle. When RMP measurements were completed, the animals were exsanguinated by abdominal aortic puncture. The first $1.0 \mathrm{ml}$ of blood was collected separately and used for electrolyte analysis. The total exsanguination procedure took less than $30 \mathrm{~s}$. The vastus and soleus muscles from the opposite side were then exposed and immediately removed for electrolyte analysis.

Serum and muscle potassium, sodium, and chloride were measured. After weighing, the muscle was dried to constant weight to determine water content. Muscle electrolyte analysis was made after nitric acid digestion of the muscle. Only plastic or acid-washed glassware was used. Sodium and potassium were measured on a flame photometer with internal lithium standard, and chloride on a Cotlove chloridimeter (Buchler Instruments Div., NuclearChicago Corp., Fort Lee, N. J.).

The partition of water and electrolytes between intraand extracellular phases was calculated on the basis of chloride space as the estimate of ECF volume (8).

\section{RESULTS}

Serum electrolyte values (mean $\pm \mathrm{SE}$ ) corrected for water content and Donnan effect were: sodium, 142.6 \pm .7 $\mathrm{meq} / \mathrm{liter}$; potassium, $4.9 \pm 0.1 \mathrm{meq} / \mathrm{liter}$; and chloride, $100.5 \pm .8 \mathrm{meq} /$ liter. Table I lists the measured in vivo RMP, intracellular potassium and sodium concentrations, and $\mathrm{E}_{\mathrm{\kappa}}$. Mean intracellular chloride concentration was $3.7 \mathrm{meq} /$ liter in white vastus, $4.8 \mathrm{meq} /$ liter in red vastus, and $4.6 \mathrm{meq} / \mathrm{liter}$ in soleus. The RMP was also calculated for each animal from the Hodgkin, Goldman. Katz $(15,16)$ equation where

$$
\mathrm{RMP}=61.5 \log \frac{\left(\mathrm{K}^{+}\right)_{\mathrm{ICF}}+0.01\left(\mathrm{Na}^{+}\right)_{\mathrm{ICF}}}{\left(\mathrm{K}^{+}\right)_{\mathrm{ECF}}+0.01\left(\mathrm{Na}^{+}\right)_{\mathrm{ECF}}} .
$$

A histogram of the RMP (Fig. 1) clearly demonstrates that there was almost no overlap of the values for RMP's when measurements were made in that part of the muscle which is composed predominantly of fastcontracting glycolytic or fast-contracting oxidative glycolytic fibers. In the small area of the muscle where these fibers intermingle, there was a mixture of both high and low RMP, and in this part of the muscle, the measured $\left(\mathrm{K}^{+}\right)_{\text {ICF }}$ and $\left(\mathrm{Na}^{+}\right)_{\text {ICF }}$ also fell between the values found where only one fiber type predominated. Values for RMP and electrolyte content from this area were therefore excluded from the analyses.

Water content was almost identical in portions of these muscles known to be composed predominantly of one fiber type, i.e., $76.7(\mathrm{SE} \pm 0.2) \%, 76.4(\mathrm{SE} \pm 0.3) \%$, and 76.3 ( $\mathrm{SE} \pm 0.2) \%$ of wet weight in white vastus, soleus, and red vastus lateralis, respectively. The percent of total water that was extracellular, as calculated 
TABLE I

Values for RMP and Ionic Distribution in Guinea Pig Muscle

\begin{tabular}{|c|c|c|c|c|c|}
\hline Muscle (fiber type) & Measured RMP & $\left(\mathrm{K}^{+}\right)_{\mathrm{ICF}}$ & $\left(\mathrm{Na}^{+}\right)_{\mathrm{ICF}}$ & $\mathrm{EK}^{*}$ & $\begin{array}{l}\text { Calculated } \\
\text { RMP }\end{array}$ \\
\hline & $m V$ & meq/liter & meq/liter & $m V$ & $m V$ \\
\hline $\begin{array}{l}\text { White vastus lateralis } \\
\text { (white, fast-twitch glycolytic) }\end{array}$ & $\begin{array}{l}-85.3 \pm 0.8 \\
(n=110)\end{array}$ & $\begin{array}{l}171.9 \pm 8.9 \\
(n=6)\end{array}$ & $50.2 \pm 4.0$ & $-94.3 \pm 1.5$ & -87.9 \\
\hline Soleus (red, slow-twitch oxidative) & $\begin{array}{c}-69.7 \pm 0.6 \\
(n=134)\end{array}$ & $\begin{array}{c}137.5 \pm 5.0 \\
(n=6)\end{array}$ & $43.9 \pm 2.3$ & $-88.2 \pm 2.7$ & -81.9 \\
\hline $\begin{array}{l}\text { Red vastus lateralis } \\
\text { (red, fast-twitch oxidative glycolytic) }\end{array}$ & $\begin{array}{l}-71.7 \pm 0.7 \\
(n=150)\end{array}$ & $\begin{array}{l}139.6 \pm 2.9 \\
(n=6)\end{array}$ & $36.0 \pm 2.7$ & $-87.8 \pm 1.1$ & -82.4 \\
\hline
\end{tabular}

All values: mean \pm SEM.

${ }^{*} \mathrm{E}_{\mathrm{K}}=-61.5 \log \frac{\left(\mathrm{K}^{+}\right)_{\mathrm{ICF}}}{\left(\mathrm{K}^{+}\right)_{\mathrm{ECF}}}$

$\ddagger$ Calculated RMP $=-61.5 \log \frac{\left(\mathrm{K}^{+}\right)_{\mathrm{ICF}}+0.01\left(\mathrm{Na}^{+}\right)_{\mathrm{ICF}}}{\left(\mathrm{K}^{+}\right)_{\mathrm{ECF}}+0.01\left(\mathrm{Na}^{+}\right)_{\mathrm{ECF}}}$.

from the chloride space and the measured RMP, while comparable in white vastus $(9.1 \pm 0.6 \%)$ and soleus $(8.2 \pm 0.7 \%)$, was significantly $(P<0.01)$ reduced in red vastus lateralis $(4.4 \pm 0.8 \%)$.
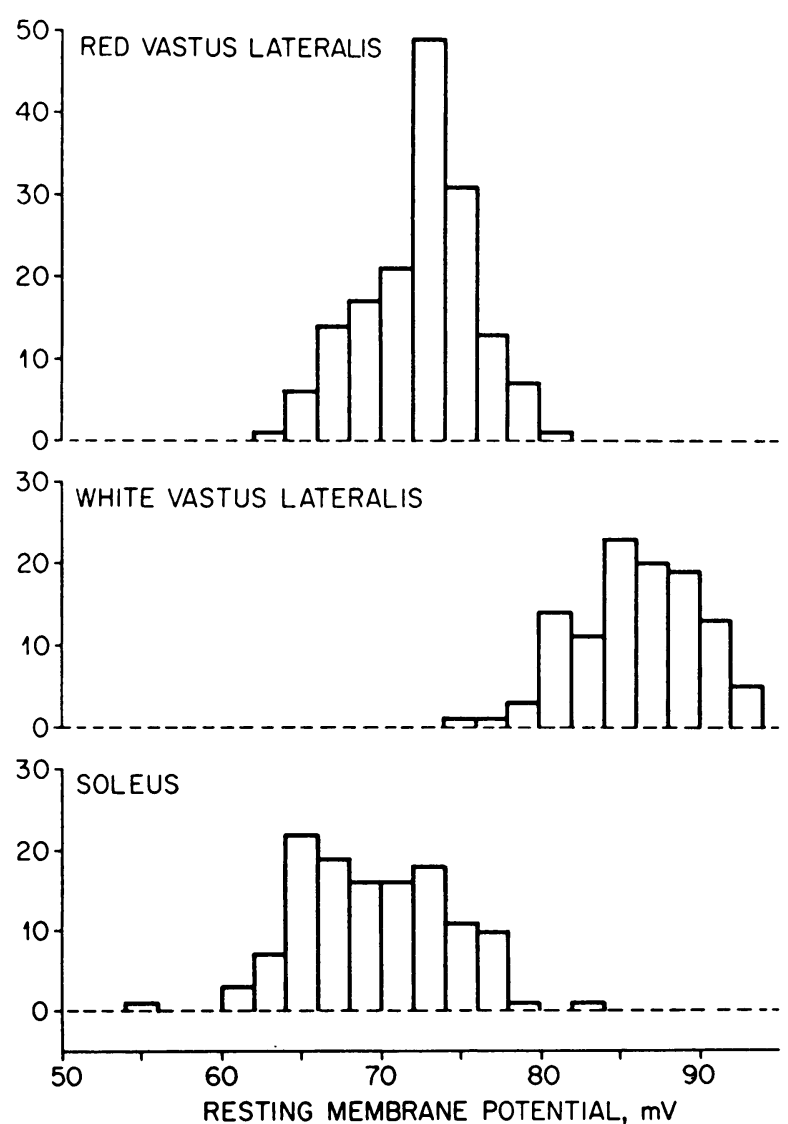

FIGURE 1 Histogram of resting membrane potential of fibers of red vastus lateralis, white vastus lateralis, and soleus muscles of the guinea pig.

\section{DISCUSSION}

The rat extensor digitorum longus and soleus muscles have been extensively studied as typical examples of fast-twitch and slow-twitch muscles. The fact that these muscles are grossly white and red respectively has led to much confusion (see Peter et al. [10] and Fiehn and Peter [20] for discussion). The guinea pig white vastus studied here is a fast-twitch muscle like the rat extensor digitorum longus, and the measured RMP of $-85.3 \mathrm{mV}$ found in this study is similar to the RMP of -78.2 and $-85 \mathrm{mV}$ found in the rat extensor digitorum longus by Yonemura (17) and Federov (18). The RMP measured here in guinea pig soleus of $-69.7 \mathrm{mV}$ also approximates the $-66 \mathrm{mV}$ Yonemura found in rat soleus. Drahota (13) in 1961 generalized to the effect that white muscles have higher intracellular potassium than red muscles, and this is supported by the intracellular potassium found in this study of $171.9 \mathrm{meq} / \mathrm{liter}$ in white vastus and $137.5 \mathrm{meq} / \mathrm{liter}$ in soleus.

The fibers of guinea pig red vastus lateralis muscle are both fast-twitch (time-to-peak tension $19 \mathrm{~ms}$ ) and grossly red. These fibers have been clearly shown to have both oxidative and glycolytic properties giving them a unique metabolic profile (12) in which features of both fast-twitch glycolytic and slow-twitch oxidative fibers are combined. The RMP of $-71.7 \mathrm{mV}$ in this muscle and the intracellular potassium concentration of $139.6 \mathrm{meq} /$ liter were as predicted by Drahota for red muscle, but less than previously observed in fast-twitch fibers. The ionic hypothesis of Hodgkin predicts that muscle with similar concentration of intracellular potassium will have approximately the same RMP. It is, therefore, not surprising that the red vastus lateralis and soleus, which have almost identical intracellular potassium concentrations, 139.6 and $137.5 \mathrm{meq} / \mathrm{liter}$, 
respectively, have similar RMP's of -71.7 and -69.7 $\mathrm{mV}$.

It is of considerable interest in Table I to compare the measured RMP's to the calculated RMP's using the usual relative permeability figure for sodium/potassium $\left(\mathrm{P}_{\mathrm{Na}}\right)$ of 0.01 . In white vastus lateralis the measured $\mathrm{RMP}$ of $-85.3 \mathrm{mV}$ is close to the calculated $-87.9 \mathrm{mV}$, but in both soleus and red vastus lateralis the calculated RMP of $-82 \mathrm{mV}$ is almost $10 \mathrm{mV}$ higher than the measured potential. If the measured R.MP is set equal to the Hodgkin, Goldman, $\operatorname{Katz}(15,16)$ equation, then solving for $P_{x a}$ gives in white vastus lateralis $P_{x a}$ equal to 0.015 , while in soleus, Pxa equals 0.041 , and in red vastus lateralis, Pxa equals 0.036 . Whether the increase in sodium permeability relative to potassium is an advantage to the fibers of soleus and red vastus lateralis, which have in contrast to white vastus lateralis the common property of greater oxidative capacity and relative resistance to fatigue, is unknown.

The total water content of the three fiber types was very similar, but the fraction of water that was extracellular was significantly less in red vastus lateralis then in soleus and white vastus lateralis. The reason for this difference is not known. As the concentration of potassium in ECF is less than $1 / 20$ th of the intracellular concentration, this variation in ECF content has negligible $(<2 \%)$ effect on calculated intracellular potassium, $\mathrm{E}_{\mathrm{k}}$, or the RMP as calculated for the Hodgkin, Goldman, Katz equation. Intracellular sodium of red vastus lateralis would, however, be decreased from 36 to $31 \mathrm{meq} /$ liter if the fraction of extracellular water was increased in red vastus lateralis to equal the 8 or $9 \%$ in white vastus lateralis and soleus.

The intracellular sodium in guinea pig muscle found here is higher than generally reported in mammalian muscle and was higher than in the same muscle taken in similar fashion from rats. Muscle electrolyte extraction and analyses were done in identical fashion; plastic was used to minimize contamination; extracellular fluid space was calculated from the chloride distribution and measured RMP. The mean ( $\pm \mathrm{SE}$ ) intracellular sodium of rat white vastus was $18.5( \pm 1.8) \mathrm{meq} /$ liter (guinea pig, $50.2 \pm 4 \mathrm{meq} /$ liter) and of rat soleus was 28.4 $( \pm 3.3) \mathrm{meq} /$ liter (guinea pig, $43.9 \pm 2.3 \mathrm{meq} /$ liter). These values in rat are similar to human muscle (8), and the higher intracellular sodium in guinea pig is apparently, therefore, due to species variation.

These results in red vastus lateralis give us the first exception to the hypothesis that fast-twitch fibers have higher intracellular potassium and higher RMP than slow-twitch fibers. These fast-twitch fibers (fast-twitch oxidative glycolytic in red vastus lateralis) have an intracellular potassium concentration and RMP similar to some slow-twitch fibers (soleus of the guinea pig) and lower than the fast-twitch glycolytic fibers as represented by white vastus lateralis. Burke, Levine, Zajac, Tsairis, and Engel (21) have proposed that there are three types of motor units which in all likelihood correspond to the three biochemical types of fibers described by Peter et al. (10), i.e., fast-twitch glycolytic (white vastus), fast-twitch oxidative glycolytic (red vastus lateralis), and slow-twitch oxidative (soleus). Studies of more fibers having the characteristics of red vastus lateralis, i.e. relative resistance to fatigue, fast-twitch, and oxidative and glycolytic capacity, must be undertaken before any pattern relating these features to RMP and intracellular potassium can be assessed.

It is obvious, therefore, that in any consideration of human or animal mammalian muscle the type of muscle being studied must be defined. To label muscle as grossly or visually red or white and not to define the actual physiological and biochemical type of fibers composing it is now indefensible.

\section{ACKNOWLEDGMENTS}

This study was supported by U.S.P.H.S. grant G.M 15759. I am indebted to Dr. James B. Peter for his comments on the manuscript and to $\mathrm{Mr}$. Robert Olsen for his excellent technical assistance.

\section{REFERENCES}

1. Goodgold, J., and A. Eberstein. 1966. Transmembrane potentials in human muscle cells in vivo. Exp. Ncurol. 15: 338-346.

2. Bolte, H. D., G. Riecke, and D. Röhl. 1963. Measurements of membrane potential of individual muscle cells in normal men and patients with renal insufficiency. Proc. Int. Conyr. Nephrol. 78: 114-117.

3. Creutzfeldt, O. D., B. C. Abbott, W. M. Fowler, and D. M. Pearson. 1963. Muscle membrane potentials in episodica adynamia. Electroencephalogr. Clin. Neurophy'siol. 15 : 508-519.

4. Johns, R. J. 1960. Microelectrode studies of muscle membrane potentials in man. Res. Publ. Assoc. Res. Neri. Ment. Dis. 38: 704-713.

5. Norris, F. H., Jr. 1962. Unstable membrane potential in human myotonic muscle. Electroencephalogr. Clin. Nenrophysiol. 14 : 197-201.

6. Brooks, J. E., and T. Hongdalarom. 1968. Intracellular electromyography. Resting and action potential in normal human muscle. Arch. Neurol. 18: 291-300.

7. McComas, A. J., K. Mrożek, D. Gardner-Medwin, and W. H. Stanton. 1968. Electrical properties of muscle fibre membranes in man. J. Neurol. Neurosurg. Psychiatry. $31: 434-440$.

8. Cunningham, J. N., Jr., N. W. Carter, F. C. Rector, Jr., and D. W. Seldin. 1971. Resting transmembrane potential difference of skeletal muscle in normal subjects and severely ill patients. J. Clin. Iniest. 50: 49-59.

9. Barnard, R. J., V. R. Edgerton, T. Furukawa, and J. B. Peter. 1971. Histochemical, biochemical and contractile properties of red, white, and intermediate fibers. Am. J. Physiol. 220: 410-414.

10. Peter, J. B., R. J. Barnard, V. R. Edgerton, C. A. Gillespie, and K. F. Stempel. 1972. Metabolic profiles of 
three fiber types of skeletal muscle in guinea pigs and rabbits. Biochemistry. 11: 2627-2633.

11. Guth, L. 1968. "Trophic" influences of nerve on muscle. Physiol. Rev. 48: 645-687.

12. Mark, R. F. 1969. Matching muscles and motoneurones. A review of some experiments on mator nerve regeneration. Brain Res. 14 : 245-254.

13. Drahota, Z. 1961. The ionic composition of various types of striated muscles. Physiol. Bohemoslov. 10: 160-165.

14. Sreter, F., and G. Woo. 1963. Cell water, sodium, and potassium in red and white mammalian muscles. Am. J. Physiol. 205: 1290-1294.

15. Hodgkin, A. L., and B. Katz. 1949. The effect of sodium ions on the electrical activity of the giant axon of the squid. J. Physiol. (Lond.). 108: 37-77.

16. Goldman, D. E. 1943. Potential, impedance and rectification in membranes. J. Gen. Physiol. 27: 37-60.
17. Yonemura, K. 1967. Resting and action potentials in red and white muscle of the rat. J. Physiol. Soc. Jap. 17: 708-719.

18. Federov, V. V. 1969. Peculiarities of bioelectric activity of fibres from fast and slow muscles in rat. Fiziol. $Z h$. (Akad. Nauk. Ukr. Rsr.). 55: 588-596.

19. Hoh, J. F. Y., and B. Salafsky. 1971. Effects of nerve cross-union on rat intracellular potassium in fasttwitch and slow-twitch rat muscles. J. Physiol. (Lond.). 216: 171-179.

20. Fiehn, W., and J. B. Peter. 1971. Properties of the fragmented sarcoplasmic reticulum from fast twitch and slow twitch muscles. J. Clin. Invest. 50: 570-573.

21. Burke, R. E., D. N. Levine, F. E. Zajac, III, P. Tsairis, and W. K. Engel. 1971. Mammalian motor units: physiological-histochemical correlation in three types in cat gastrocnemius. Science (Wash. D. C.). 174: 709712. 